\title{
Knowledge and attitude toward organ donation of medicine students of a Northeastern Mexico Public University
}

\author{
María José Sebastián-Ruiz', Elda Karina Guerra-Sáenz', Anna Karen Vargas-Yamanaka1, \\ Oralia Barboza-Quintana ${ }^{3}$, Antonio Ríos-Zambudio ${ }^{4}$, Ricardo García-Cabello² and \\ Gerardo del Carmen Palacios-Saucedo² \\ ${ }^{1}$ Hospital Coordination for Organ Donation; ${ }^{2}$ Health Research Division, High Specialty Medical Unit, Specialty Hospital No. 25 Centro Médico \\ Nacional Noreste, Instituto Mexicano del Seguro Social, Monterrey; ${ }^{3}$ Subdirection, Faculty of Medicine, Universidad Autónoma de Nuevo León, \\ Monterrey, N.L., Mexico; ${ }^{4}$ Department of Surgery, Transplantation Unit, Hospital Universitario Virgen de la Arrixaca, Murcia, Spain
}

\begin{abstract}
Objective: The objective of this study was to evaluate the knowledge and attitude toward organ donation of medicine students of a Northeastern Mexico public university. Methods: This was a prolective, descriptive, observational, and cross-sectional study. A 34 items cross-sectional survey evaluating knowledge and attitude toward organ donation in 3056 medicine students during 2013-2015. Descriptive statistics were used as absolute frequencies, percentages, mean and standard deviation, as well as the Chi-square test. $p<0.05$ was considered statistically significant. Results: About $74 \%$ of students would donate their own organs, mainly due to reciprocity (41\%). $26 \%$ of students would not donate, $48 \%$ of them due to fear that their organs could be taken before death. $86 \%$ would donate organs from a relative. $64 \%$ have spoken about organ donation and transplantation with their family and $67 \%$ with friends. $50 \%$ said they had received no information about it. $68 \%$ understand the concept of brain death. Conclusion: Students received little information about organ donation during college. Despite that, most of them showed a positive attitude and are willing to donate.
\end{abstract}

KEY WORDS: Organ donation. Attitude. Students. Brain death. Transplants. Organs and tissues.

\section{Introduction}

Organ transplantation has been widely accepted as a definitive treatment for organ end-stage disease, and as a result of the increase in chronic diseases, the need for organs grows in parallel. In spite of the positive attitude of the general population toward organ donation, the current number of donors is significantly lower than the number of patients waiting for an organ. This discrepancy represents a challenge for health systems worldwide'.

Health professionals are a key link in the process of organ and tissue donation for transplantation and, therefore, the influence on the perception of society about organ donation, on the one hand, as educators on health for patients and their families during healthcare, and on the other, as a fundamental element in the care of the hospitalized patient in the context of a devastating cerebral event that might develop into brain death. Doctors receive academic information on multiple and diverse subjects, but the organ donation subject is barely or not addressed during medical training ${ }^{2}$.

The cessation of the cardiopulmonary function has traditionally been regarded as a point of reference to pronounce a person's death. Similarly, complete and

\author{
Correspondence: \\ Gerardo del Carmen Palacios Saucedo \\ Avda. Fidel Velásquez y Lincoln, s/n \\ Col. Nueva Morelos \\ C.P. 64320 , Monterrey, N.L., México \\ E-mail: palsaugc@gmail.com; \\ gerardo.palacios@imss.gob.mx
}

Date of reception: 03-06-2016

Date of acceptance: 03-06-2016

DOI: 10.24875/GMM.M17000021
Gac Med Mex. 2017;153:395-404

Contents available at PubMed www.gacetamedicademexico.com 
irreversible loss of cerebral hemispheres and brainstem function also equates to loss of life, both from the biological and legal and ethical point of view. It is characterized by deep coma, the absence of brainstem reflexes and apnea. Identification of such situation is vital for the donation program as an organ-generating source. Brain death detection is an essential task, hence the need of an adequate follow-up of patients with acute neurological damage who might become donors ${ }^{3}$.

Transplantation programs depend largely on cadaveric donation, of patients with brain death. Each cadaveric donor can save the lives of at least six persons, restore vision to two, and help hundreds through bone donation. Therefore, since living donation cannot resolve the needs for all organs, donation after brain death constitutes an excellent alternative or the only possibility. One of the main challenges faced by a transplantation program is to obtain a favorable decision of the family in relation to donating their deceased relative's organs. This requires objective information, but delicately put, clearly, but with empathy; hence, the need for the doctor to have the ability to convey the long-range effects such an unselfish, caring act of love might represent to people waiting for an organ. The acquisition of such skills is not the fruit of casualty; it should be developed and practiced since the training stage of medical students ${ }^{4}$.

There are studies in foreign universities about medical students' knowledge and attitude with regard to organ donation. The present work is the first one of this kind in Mexico with a large sample $(n=3000)$. The purpose of this study is to find out the attitude and knowledge of medical students from a northwestern Mexico public university on organ and tissue donation.

\section{Methods}

The study had a descriptive, observational, and protective design, in the form of a survey. The study was conducted at the Faculty of Medicine of the Autonomous University of Nuevo Leon (UANL - Universidad Autónoma de Nuevo León), Monterrey, N.L., during the 2013-2015 period. The surveys were applied to 3056 students at different years of the undergraduate medical education program. Surveys with $<80 \%$ of answered items (27/34) and those that were not returned were censored.

The surveys were self-administered and were applied at an adequate place that was comfortable for the students. Attitude and general knowledge in regard to organ donation and transplantation were evaluated. The surveys consisted of 34 multiple-choice questions and were obtained from a validated questionnaire on attitude toward organ donation and transplantation (PCID-DTO RIOS: "Donor International Collaborative Project" questionnaire on organ donation and transplantation developed by Rios et al.) (Appendix $)^{5-7}$. Students' attitude toward organ donation, sociodemographic aspects, prosocial behavior, information and knowledge on organ donation, family, social and socio-cultural interactions and attitude toward the body were assessed from each questionnaire.

In the domain regarding general information on organ donation and transplantation, information obtained by any means was considered to be positive when it expressed acceptance about organ donation, and negative information was regarded as that which included or contained refusal or rejection toward donation. In the knowledge about organ donation domain, understanding of brain death was considered to be positive when the respondent understood that a person in that state was unable to recover and lead a normal life.

The data were collected and analyzed with the SPSS statistical package, version 21. Absolute frequencies, percentages, means, standard deviation, and the Chi-square test, were used. $p<0.05$ was considered to be significant.

\section{Results}

A total of 3056 interviews were included; students' mean age was $20.3 \pm 2.4$ years; $53.3 \%$ were males and $46.7 \%$ were females; $93 \%$ had the Mexican nationality, and $27.7 \%$ were at $1^{\text {st }}$ year of the undergraduate medical education program. Up to $74 \%$ of the students would be willing to donate their organs, and the main reason to do it would be reciprocity in $41 \%$; of $26 \%$ of students who would not donate their organs, $48 \%$ referred fear of their organs being taken before being dead as the main reason not to do it. Among the students' prosocial attitudes, $67 \%$ were found not to be blood donors but would be willing to, and $58 \%$ did not collaborate in non-government organizations, voluntary service or social assistance, but would be willing to do it.

Regarding information and knowledge about organ and tissue donation, $24 \%$ of the surveyed students were found to know somebody who had required or received an organ transplantation, $90 \%$ did not know 


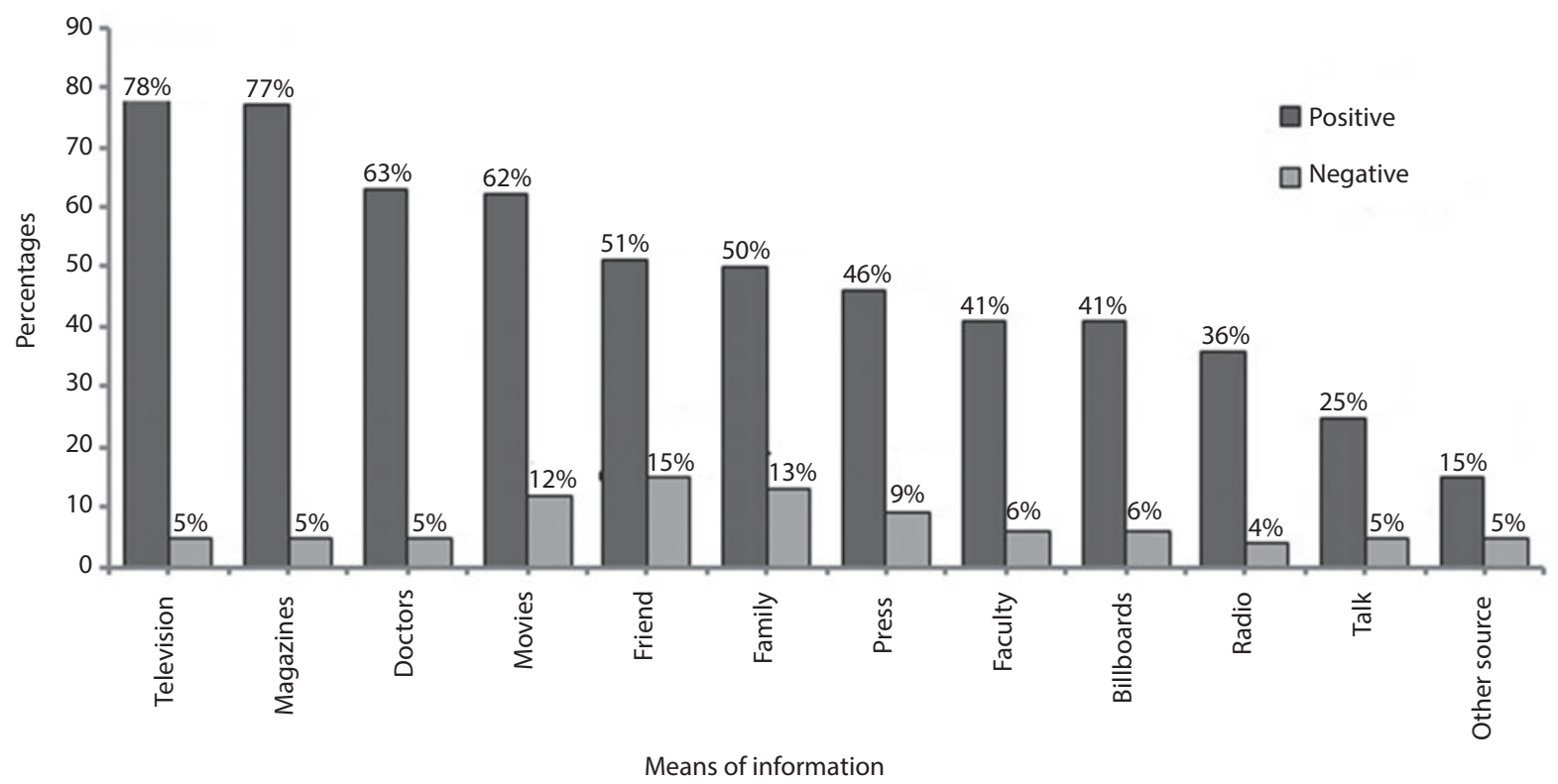

Figure 1. Means through which 3056 medical students from a public university of northeastern Mexico received information on organ donation and transplantation, classified according to whether such information was positive or negative.

anybody who had donated organs y, and $94 \%$ believed that the needs for organ donation and transplantation were not covered. $50 \%$ had received some talk about organ donation and transplantation and $78 \%$ considered a talk about donation would be interesting for them. Of the surveyed students, $37 \%$ considered their knowledge on organ donation to be normal, and $33 \%$ considered it to be poor; the means of communication the surveyed students had obtained information on donation and transplantation from was mainly television, with $78 \%$ (Fig. 1). When the knowledge about the causes a person may require a transplant for was assessed, $73 \%$ considered the need for an organ transplantation during their lives as a consequence of any disease to be possible, and when assessing the knowledge about the consequences of donating an organ, the surveyed students stated that donating a segment of the liver $(48 \%)$ or one kidney (55\%) while still alive entailed some risk for the donor. With regard to the level of understanding of the brain death concept, $68 \%$ understood the concept, $23 \%$ had doubts, and $9 \%$ did not understand it.

When the students' familiar and social interactions were assessed, $64 \%$ were found to have discussed the organ donation, and transplantation subject with their families and, within the family, mothers mostly expressed a favorable opinion (48\%) in comparison with fathers (41\%); $67 \%$ had addressed the subject with friends, and $30 \%$ were unaware of their boy/girlfriends' opinion (Fig. 2). $86 \%$ would be willing to donate some relative's organs. $70 \%$ would be willing to accept a liver transplantation donated by some living relative in case of requiring it. $94 \%$ would donate one kidney, and $91 \%$ would donate a liver segment to a relative, but only $51 \%$ would donate one kidney, and $52 \%$ a liver segment to any other person requiring it (Fig. 3).

Within socio-cultural characteristics, $40 \%$ of the students were found to be non-practicing Catholics, and $59 \%$ believed their religion was in favor of organ donation and transplantation. 33\% would consider an abuse of authority a legislation that would allow the state to make use of corpses' organs without previous authorization, $31 \%$ considered this an efficacious measure to avoid wasting, $17 \%$ considered this as an offense to the family of the deceased, and $13 \%$ as a gesture of solidarity. $40 \%$ completely trusted their family doctors. In regard to medical students attitudes toward the body, $57 \%$ would not mind their body being left with scars or mutilated after the donation of one of their organs and, after their own death or the death of a relative, $79 \%$ would agree on the performance of an autopsy, $71 \%$ would prefer cremation and $54 \%$, inhumation.

A significant difference was observed when students who would be willing or not to donate their organs were compared according to gender (males: 1094/1561, 70\%; females: 1074/1365, 79\%; $p<0.001$ ), by age groups $(p<0.001)$, according to ongoing 


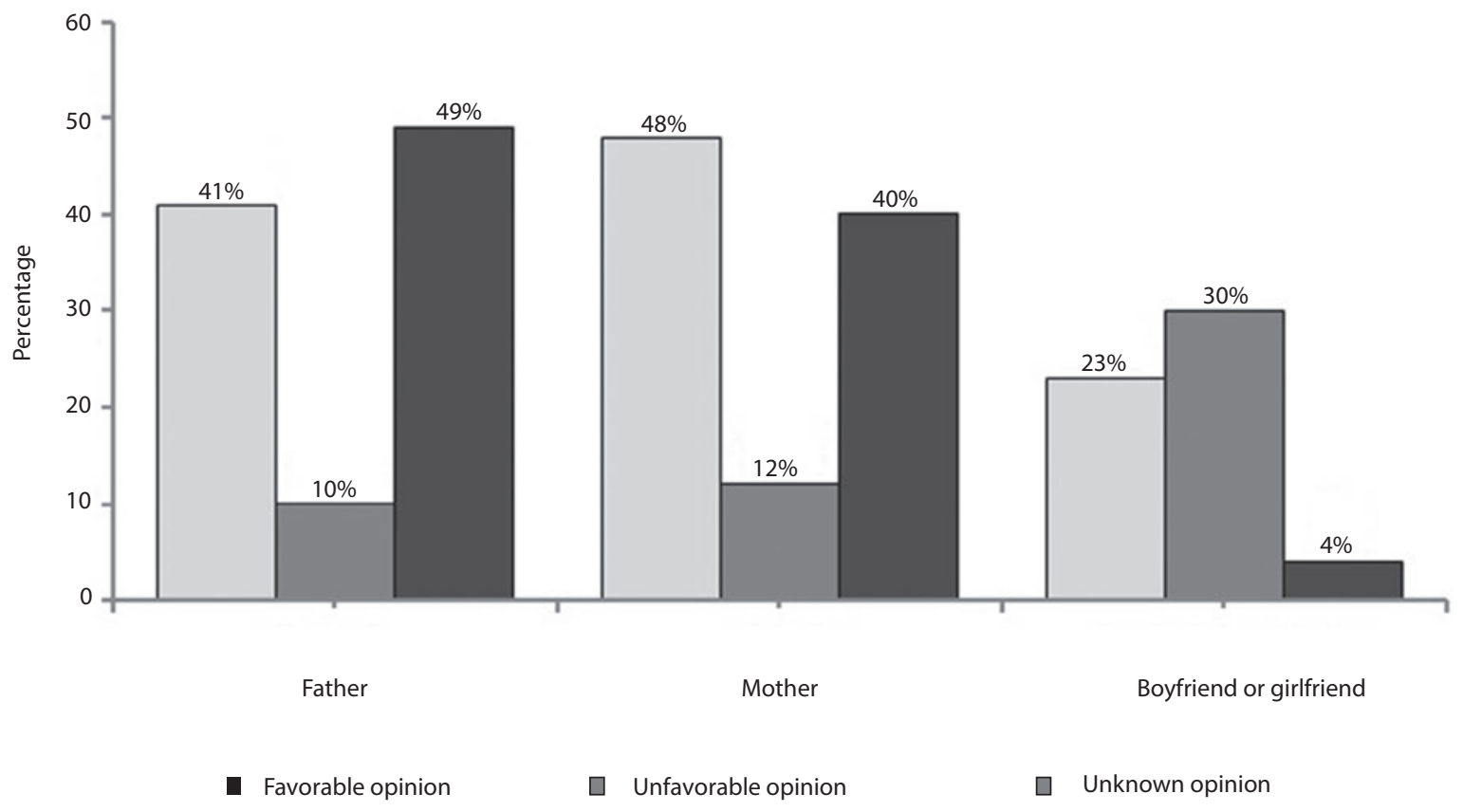

Figure 2. Answer to the question "Do you know your parents' and your boy/girlfriend's opinion about organ donation and transplantation?" given by 3056 medical students from a public university of northeastern Mexico.

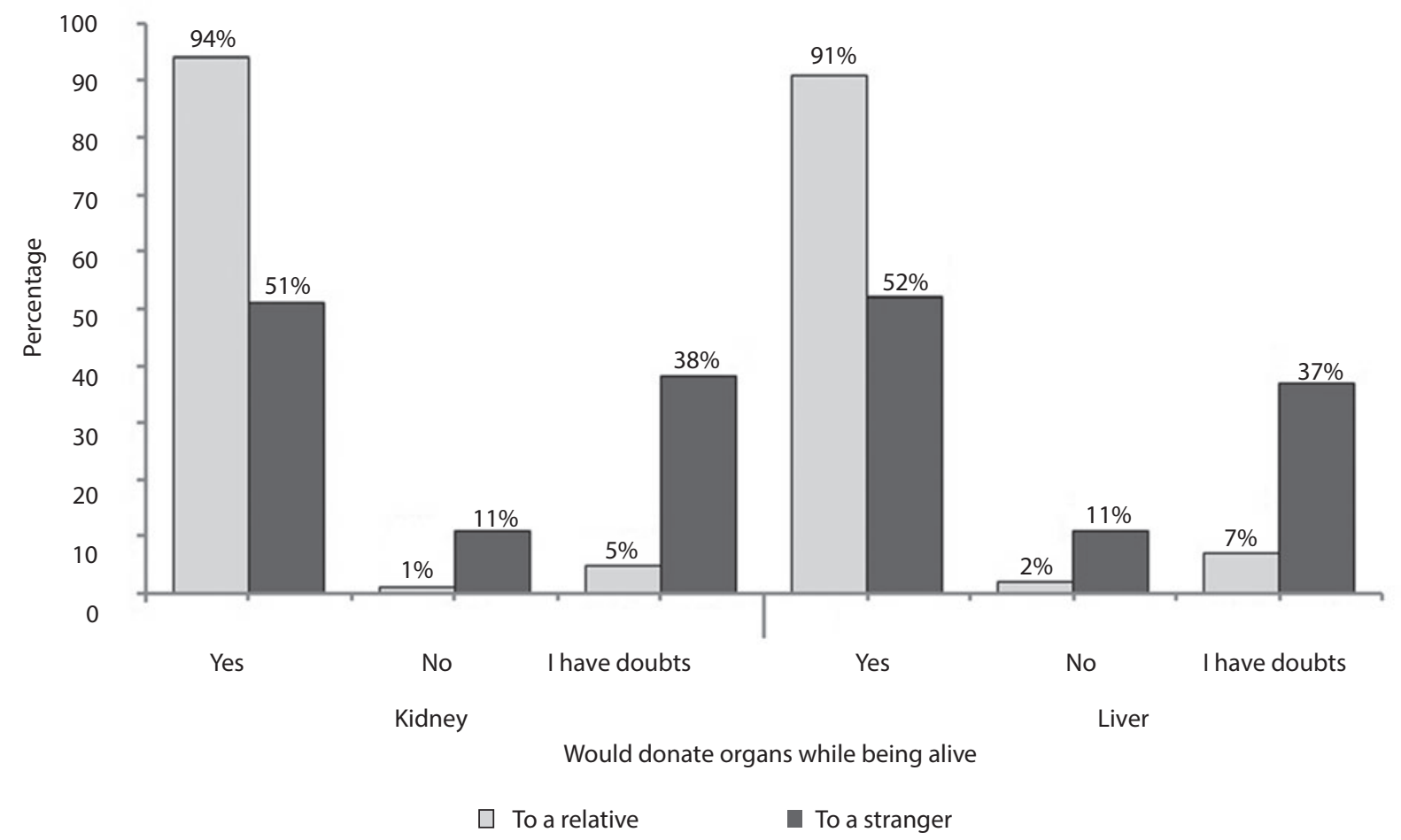

Figure 3. Answer to the question "Would you donate an organ as a living donor?" given by 3056 medical students from a public university of northeastern Mexico, classified according to whether the donation would be of one kidney or a portion of the liver to a relative or a stranger. 
Table 1. General characteristics, undergraduate year and information received about donation in 3056 medical students from a public university of northeastern Mexico and their attitude toward organ donation

\begin{tabular}{|c|c|c|c|c|c|}
\hline & \multicolumn{4}{|c|}{ Would donate his/her organs } & \multirow[t]{2}{*}{$\mathrm{p}$} \\
\hline & Yes & No & Has doubts & Total & \\
\hline \multicolumn{6}{|l|}{ Gender } \\
\hline Female & $1074(78.7 \%)$ & $36(2.6 \%)$ & $255(18.7 \%)$ & 1365 & \multirow[t]{2}{*}{$<0.001$} \\
\hline Male & $1094(70.1 \%)$ & $99(6.3 \%)$ & $368(23.6 \%)$ & 1561 & \\
\hline \multicolumn{6}{|c|}{ Age (years) } \\
\hline $17-20$ & $1110(69.7 \%)$ & $83(5.2 \%)$ & $399(25.1 \%)$ & 1592 & \multirow[t]{5}{*}{$<0.001$} \\
\hline $21-25$ & $899(80.1 \%)$ & $44(3.9 \%)$ & $179(16.0 \%)$ & 1122 & \\
\hline $26-30$ & $51(82.3 \%)$ & $3(4.8 \%)$ & $8(12.9 \%)$ & 62 & \\
\hline $31-35$ & $3(50 \%)$ & $2(33 \%)$ & $1(17 \%)$ & 6 & \\
\hline $36-40$ & $4(100 \%)$ & $0(0 \%)$ & $0(0 \%)$ & 4 & \\
\hline \multicolumn{6}{|c|}{ Undergraduate year } \\
\hline 1 & $561(68.3 \%)$ & $43(5.3 \%)$ & $217(26.4 \%)$ & 821 & \multirow[t]{6}{*}{$<0.001$} \\
\hline 2 & $290(72.5 \%)$ & $14(3.5 \%)$ & $96(24.0 \%)$ & 400 & \\
\hline 3 & $345(69.8 \%)$ & $28(5.7 \%)$ & $121(24.5 \%)$ & 494 & \\
\hline 4 & $309(79.4 \%)$ & $19(4.9 \%)$ & $61(15.7 \%)$ & 389 & \\
\hline 5 & $353(86.9 \%)$ & $10(2.5 \%)$ & $43(10.6 \%)$ & 406 & \\
\hline 6 & $179(82.9 \%)$ & $5(2.3 \%)$ & $32(14.8 \%)$ & 216 & \\
\hline \multicolumn{6}{|c|}{ Received talk on organ donation } \\
\hline Yes & $1174(79.5 \%)$ & $50(3.4 \%)$ & $252(17.1 \%)$ & 1476 & \multirow[t]{2}{*}{$<0.001$} \\
\hline No & $1013(68.7 \%)$ & $85(5.8 \%)$ & $377(25.5 \%)$ & 1475 & \\
\hline
\end{tabular}

undergraduate year $(p<0.001)$ and according to whether they had received a talk about organ donation and transplantation (did receive one: 1174/1476, 80\%; did not receive one: $1013 / 1475,69 \% ; p<0.001)$ (Table 1). When the understanding of the brain death concept was compared according to the undergraduate year, the higher the number of completed years was observed to result in higher numbers of students with such understanding (the concept was understood by $465 / 834,56 \%$ of $1^{\text {st }}$ year students, as compared with $195 / 222,88 \%$ of $6^{\text {th }}$ year students; $p<0.001$ ) (Table 2).

\section{Discussion}

There are studies that have reported the knowledge and attitude of medical students with regard to organ donation in foreign universities, with different curriculum to that used in our country's public universities ${ }^{8}$. However, there are no studies of this sort conducted in Mexico, and the present work, with over 3,000 students, might, therefore, be a reflection of the opinion on the subject future health professionals have in other states or similar countries.

The results of the present study, similar to observations reported by Kose et al. ${ }^{9}$ in 2015, show that at least one-fourth of the surveyed individuals had received information on the subject and knew somebody who required or had received an organ transplantation, which is also similar to Najafizadeh et al. ${ }^{10}$ findings. In those who had received information, television was the main means of diffusion, which is consistent with reports by other authors ${ }^{4,9}$.

Although three-quarters of the surveyed students expressed being willing to donate their organs, half of them would do it only if it was for some relative. The main reason for willingness to donate was reciprocity, while other groups report that it is the ethically and morally right thing to do and the best way to help others ${ }^{4,9}$.

In this study, the main reason not to donate was fear of organs being taken before being dead. In other studies, the idea prevailed that the person should be buried with his/her intact organs, or that donation represented an unacceptable mutilation ${ }^{1,4,8,9}$. The fact that half the students that would not donate express fear that organs could be taken before being really dead would seem to demonstrate mistrust toward the health system or lack of real understanding of the meaning of brain death, i.e. loss of life that is equivalent to "traditional death" due to irreversible cardiorespiratory arrest. More than half the students referred understanding the brain death concept, especially those who were at higher undergraduate years, similar to the report of a CENTARA previous study ${ }^{11}$, and lower to findings described by 
Table 2. Understanding of the brain death concept in $\mathbf{3 0 5 6}$ medical students from a public university of northeastern Mexico according to college year

\begin{tabular}{lcccc}
\hline & \multicolumn{3}{c}{ Understands the brain death concept (\%) } & p \\
\cline { 2 - 3 } & \multicolumn{1}{c}{ Yes } & No & Doesn't know & Total \\
\hline Undergraduate year & & & & \\
1 & $465(55.8 \%)$ & $106(12.7 \%)$ & $263(31.5 \%)$ & 834 \\
2 & $250(61.4 \%)$ & $48(11.8 \%)$ & $109(26.8 \%)$ & 407 \\
3 & $347(68.9 \%)$ & $41(8.1 \%)$ & $116(23.0 \%)$ & 504 \\
4 & $318(79.7 \%)$ & $26(6.5 \%)$ & $55(13.8 \%)$ & 399 \\
5 & $333(81.0 \%)$ & $23(5.6 \%)$ & $55(13.4 \%)$ & 411 \\
6 & $195(87.8 \%)$ & $9(4.1 \%)$ & $18(8.1 \%)$ & 222 \\
\hline
\end{tabular}

Najafizadeh et al. $^{10}$ and Tawil et al. $^{12}$ in their studies.

The present work revealed that two-thirds of surveyed individuals had talked about donation with their family or friends, which is a higher figure than those found by Symvoulakis et al. ${ }^{8}$ and by other surveys carried out in the general population in $\mathrm{Mexico}^{13}$. These students showed a more favorable attitude toward donation than those who hadn't done it. We consider it is of paramount importance addressing the subject with the family to identify attitudes and for these to be eventually respected.

As regard living organ donation, practically all students expressed being willing to donate one kidney or liver segment to some relative, and half of them, to a non-related person, especially to children. The majority is concerned about surgical risks or later impact on the donor's health ${ }^{14}$. Also unanimously, they would be willing to accept an organ from a relative in case they needed, which is in contrast with studies in other countries, where nearly half of respondents would not feel comfortable with the possibility of receiving an organ from some relative ${ }^{14}$.

In the light of the possibility of legislative modifications that would allow making use of dead persons' organs without previous authorization, although onethird considered it to be an efficacious method in order for organs not to be wasted, half the students perceived this as an abuse of authority or an offense to the family of the deceased, and an only a small proportion saw it as a gesture of solidarity. These results are consistent with opinions expressed by Greek students, who were in favor of prohibiting unauthorized organ removal after any individual's death ${ }^{8}$.

Talking about an organ donation successful process would imply, among other things, availability of trained, sensitive professionals willing to honestly offer information to the family of a patient with brain death. Still today, this constitutes a barrier for different reasons: lack of knowledge, lack of time, sense of therapeutic failure, etc., which make for potential donors less likely to be identified and become involved in the process ${ }^{15}$. Radunz et al. ${ }^{16}$ argue that a positive attitude of health professionals and adequate information can positively influence on the decision of the family members by helping for misconceptions or myths about donation to be eradicated. Educating doctors on this subject since their student years is crucial ${ }^{17}$.

In this same direction, Cheung et al. ${ }^{18}$ proposed a Selected Study Model to allow students to explore medical areas that are not part of the regular curriculum, and García et al. ${ }^{19}$, in Brazil, implemented a course directed to undergraduate medical students where subjects such as brain death diagnosis, donor potential preservation, legal aspects, and main organs' transplantation were addressed.

Similarly, in Spain, the University of Barcelona and the National Organization of Transplantation developed an international educational project (transplant procurement management) on donation and transplantation to educate and motivate professionals involved in the process of donation and transplantation. Its main goal was to increase organ and tissue availability by creating awareness that organs are social goods ${ }^{20}$. As students and interns become involved in identifying patients with brain death, transplantation hospital programs will be benefited ${ }^{3}$.

The factors more strongly associated with the donor status (being or not being one), other than the cognitive ones, are factors of social nature, altruism, solidarity, participation in non-government associations, and other social-oriented works. Society and technology evolve hand in hand, and individuals have adopted trends marked by social networks, which may positively impact on organ donation by inviting the population to become donors ${ }^{20}$. Linking "viral" social networks with social causes represent an effective communication strategy with regard to organ donation ${ }^{21}$. Studies conducted at 
Johns Hopkins Hospital describe that the rates of donor registry increased once Facebook enabled users to specify the "Organ donor" status as part of their profile from 2012 onward. A small impact can multiply by means of an enormous communication network, which might be sufficient to eventually save many lives ${ }^{22}$.

Different collaborative studies with Spain, the country with the highest donation rate worldwide, revealed that the attitude toward a donation of health professionals, medical trainees and administrative personnel of hospitals in our country was similar or even more favorable than in workers of Spanish centers, with real knowledge about brain death also being better ${ }^{23-25}$. This theoretical similitude is in contrast with the disparity in donation productivity, which is still very low in Mexico and, curiously, donation rates of Latin American residents in Spain are much higher than those in their countries of origin ${ }^{23}$. The experience acquired over decades with donation and transplantation procedures in Spain, professionalization of such activity and universal access of the population to transplantation programs are factors that likely motivate organ donation acceptance ${ }^{24}$. It is more convincing "to give" when people know they will have the possibility "to receive" if it's required.

The results of the present study show that very few students have received information on organ donation at their arrival to college. Notwithstanding, the vast majority showed a favorable attitude and would be willing to donate an organ of their own, both while being alive and after death. The level of understanding about brain death was acceptable. This is in contrast with the low rate of donation in our country. The surveyed subjects considered donation as an altruistic and voluntary act that should not be the result of an obligation. The diffusion of these topics among the population since early ages, making an emphasis during the health personnel training stage, should constitute a key factor to enable to donation increase in Mexico in the future. The doctor will play a key role in this life recycling process.

\section{REFERENCES}

1. Bener A, El-Shoubaki H, Al-Maslamani Y. Do we need to maximize the knowledge and attitude level of physicians and nurses toward organ donation and transplant? Exp Clin Transplant. 2008;6:249-53.

2. Ríos A, López-Nava A, Ayala-García M, et al. Knowledge of the brain death concept by personnel in Spanish and Latin-American healthcare centers. Int J Artif Organs. 2014;37:336-43.
3. Patwardhan SS, Kulkarni GV. Improving the rates of cadaver organ donation in a tertiary care transplant center: A role for medical students and ancillary staff. Postgrad Med. 2011;57:347-9.

4. Ali NF, Qureshi A, Jilani BN, et al. Knowledge and ethical perception regarding organ donation among medical students. BMC Med Ethics. 2013;14:1-7. (Consultado el 15 de agosto de 2015.) Disponible en: http:// www.biomedcentral.com/1472-6939/14/38.

5. Ríos A, Ramírez P, Galindo PJ, et al. Primary health care personnel faced with cadaveric organ donation: A multicenter study in South-Eastern Spain. Clin Transplant. 2008;22:657-63.

6. Ríos A, Ramírez P, Martínez L, et al. Are personnel in transplant hospitals in favor of cadaveric organ donation? Multivariate attitudinal study in a hospital with a solid organ transplant program. Clin Transplant. 2006;20:743-54.

7. Ríos $A$, Cascales $P$, Martínez $L$, et al. Emigration from the British Isles to South-Eastern Spain: A study of attitudes toward organ donation. Am J Transplant. 2007;7:2020-30.

8. Symvoulakis E, Rachiotis G, Papagiannis D, et al. Organ donation knowledge and attitudes among health science students in Greece: Emerging interprofessional needs. Int J Med Sci. 2014;11:634-40.

9. Kose O, Onzuz M, Topuzoglu A. Knowledge levels of and attitudes to organ donation and transplantation among university students. North Clin Ist. 2015;2:19-25.

10. Najafizadeh K, Shiemorteza M, Jamali M, et al. Attitudes of medical students about brain death and organ donation. Transplant Proc. 2009;41:2707-10.

11. Parametría Investigación Estratégica Análisis de Opinión y Mercado. Donación y trasplante de órganos, reporte comparado. Centro Nacional de Trasplantes. 2007. (Consultado el 1 de enero de 2016.) Disponible en: www.cenatra.salud.gob.mx/interior/difusion_campanas_estudios_encuestas.html

12. Tawil I, Gonzales SM, Marinaro J, et al. Do medical students understand brain death? A survey study. J Surg Educ. 2012;69:320-5.

13. Sistemas de Inteligencia en Mercado y Opinión. Evaluación sobre percepción de donación de órganos como insumo para la articulación de una estrategia de comunicación. Centro Nacional de Trasplantes. 2008. (Consultado el 1 de enero de 2016.) Disponible en: www.cenatra.salud. gob.mx/interior/difusion_campanas_estudios_encuestas.html

14. Tong A, Chapman J, Wong G, et al. Public awareness and attitudes to living organ donation: Systematic review and integrative synthesis. Transplantation. 2013;96:429-37.

15. Marqués-Lespier J, Ortiz-Vega NM, Sánchez MC, et al. Knowledge of and attitudes toward organ donation: A survey of medical students in Puerto Rico. P R Health Sci J. 2013;32:187-93.

16. Radunz S, Benko T, Stern S, et al. Medical student's education on organ donation and its evaluation during six consecutive years: Results of a voluntary, anonymous educational intervention study. Eur J Med Res. 2015;20:23.

17. Radunz $S$, Juntermanns $B$, Heuer $M$, et al. The effect of education on the attitude of medical students towards organ donation. Ann Transplant. 2012;17:140-4.

18. Cheung CL, Brown J, Chesser AMS. A student-led programme to raise awareness of organ donation. Clin Teach. 2007;4:165-9.

19. Garcia CD, Barboza AP, Goldani JC, et al. Educational program of organ donation and transplantation at medical school. Transplant Proc. 2008;40:1068-9.

20. Paez G, Valero R, Manyalich M. Training of health care students and professionals: A pivotal element in the process of optimal organ donation awareness and professionalization. Transplant Proc. 2009;41:2025-9.

21. D'Alessandro AM, Peltierc JW, Dahlc AJ. The impact of social, cognitive and attitudinal dimensions on college students' support for organ donation. Am J Transplant. 2012;12:152-61.

22. Cameron AM, Massie AB, Alexander CE, et al. Social media and organ donor registration: The Facebook effect. Am J Transplant. 2013; 13:2059-65.

23. Ríos A, López-Navas A, Navalón JC, et al. The Latin American population in Spain and organ donation. Attitude toward deceased organ donation and organ donation rates. Transpl Int. 2014;28:1-11.

24. Ríos A, López-Navas A, Ayala-García MA, et al. Multivariate analysis to determine the factors affecting the attitudes toward organ donation of healthcare assistants in Spanish and Mexican healthcare centers. Transplant Proc. 2012;44:1479-81.

25. Ríos A, López-Navas A, Ayala-García MA, et al. Attitudes of Spanish and Mexican resident physicians faced with solid organ donation and transplantation. Transplant Proc. 2010;42:233-8. 


\section{APPENDIX}

\section{Questionnaire on organ donation and transplantation (college students)}

Read carefully the survey and cross or circle the chosen option. Select several options if you consider that any question has more than one possible answer. Thank you for your collaboration.

Semester:

Gender: Male Female

Age: Nationality:

1) Among your family or friends, have you met anybody who has required or received an organ transplantation?
a. Yes
b. No

2) Among your family and friends, have you met anybody who has donated organs?
a. Yes
b. No

3) Do you think the needs for organs for transplantation are covered?
a. Yes
b. No

4) Have you received any talk about organ donation and transplantation?
a. Yes
b. No

5) If you had to decide, would you donate some relative's organs?
a. Yes
b. No

6) Have you discussed the organ donation and transplantation subject with your family?
a. Yes
b. No

7) Have you discussed the organ donation and transplantation subject with your friends?
a. Yes
b. No

8) Indicate by means of which sources have you obtained information about organ donation and whether it was positive $(+)$ or negative:

\begin{tabular}{l}
\hline \\
a. Television \\
b. Radio \\
c. Magazines, books, brochures \\
d. Press \\
e. Movies \\
f. Friends \\
g. Family \\
h. Billboards or hoardings \\
i. Health personnel or doctors \\
j. Schools \\
k. Talks in other centers \\
l. None \\
m. Other
\end{tabular}

9) Would you donate your organs?
a. Yes
b. No
c. I have doubts

10) If you are in favor, for which of these reasons would you donate your organs when you die? (you can indicate more than one)
a. For considering it a moral obligation
b. For solidarity
c. For wanting to survive my own death
d. For religious reasons
e. Because it's free
f. For reciprocity (doing for others what I would like for me)
g. Other
h. I am against donation 
11) If you are against, for which of the following reasons? (you can indicate more than one)
a. Because no money is paid
b. For rejection of the idea of body mutilation
c. Out of fear that organs are removed be- fore being dead
d. For religious reasons
e. I don't want to express my reasons
f. Other
g. I am in favor of donation

12) Are you a blood donor?
a. Yes, regularly
b. Yes, occasionally
c. No, but I would be willing to
d. No, and I won't be

13) If you were to donate your organs, would you be worried about your body being left with scars or mutilated after your organs were extirpated?
a. Yes, I am very concerned
b. It's all the same to me
c. I don't know

14) Do you know your father's opinion about organ donation?
a. Yes, it is favorable
b. I don't know it
c. Yes, he is against it

15) Do you know your mother's opinion about organ donation?
a. Yes, it is favorable
b. I don't know it
c. Yes, she is against it

16) If you have boy or girlfriend, do you know his/ her opinion about organ donation?
a. Yes, it is favorable
b. I don't know it
c. Yes, he/she is against it

17) Do you think you might need an organ transplantation sometime?
a. No, because I lead a healthy life
b. There is the possibility that sometime I may fall ill and require an organ
c. I don't know

18) Do you believe a talk about organ donation would be interesting to you?
a. Yes
b. No
c. I don't know, I would have to listen to it

19) Do you consider your information about organ donation to be...?
a. Good
b. Normal
c. Scarce
d, Poor
e. Null

20) Do you trust your family doctor?
a. Absolutely
b. Fairly
c. Not so much
d. Don't trust

21) Do you collaborate with non-government organizations, voluntary service or social assistance activities?
a. Yes, regularly
b. Yes, occasionally
c. No, and I won't participate
d. No, but l'd be willing to

22) Of the following questions with regard to your own death or that of a close relative, which do you agree with?
a. I would ask for cremation Yes No
b. I would ask for inhumation Yes No
c. I would accept an autopsy Yes No

23) In your opinion, can a person with brain death recover and live normally?
a. Yes
b. No
c. I don't know

24) Since we have two kidneys, and currently one of them can be donated, would you donate one of your kidneys as a living donor to someone who needed it?
a. Yes, I would donate it
b. No, I wouldn't donate it
c. I have doubts

25) Do you think living donation of one kidney entails risk for the donor?
a. Much
b. A lot
c. Some
d. Barely any
e. I don't know

26) If one of your family members (parents, children, siblings) needed one kidney, would you donate it as a living donor?
a. Yes, I would donate it
b. No, I wouldn't donate it
c. I have doubts 
27) If you suffered from a kidney disease that required kidney transplantation, would you accept one kidney from one of your living relatives or would you hold on waiting list for one kidney to appear?
a. Yes, I would accept it
b. No, I would hold on waiting list
c. I have doubts

28) We only have one liver but, currently, it can be split and give one part to someone who is waiting for a liver transplantation. Would you donate part of your liver as a living donor to someone who needed it?
a. Yes, I would donate it
b. No, I wouldn't donate it
c. I have doubts

29) Do you think living donation of part of the liver entails risk for the donor?
a. Much
b. A lot
c. Some
d. Barely any
e. I don't know

30) If one of your relatives needed a liver, would you give him/her part of yours as a living donation?
a. Yes, I would donate it
b. No, I wouldn't donate it
c. I have doubts

31) If you needed a liver transplantation, would you accept that a direct relative would give you part of his/her liver as a living donation?
a. Yes, I would accept it
b. No, I would hold on waiting list
c. I have doubts

32) With regard to religious attitude, you consider yourself...
a. Practicing catholic
b. Non-practicing catholic
c. Non-catholic religion
d. Agnostic-atheist

33) Which of the following statements do you believe is your religion's opinion with regard to organ donation and transplantation?
a. It is in favor of organ donation and transplantation
b. It is against organ donation and transplantation
c. It has not pronounced itself on the subject

34) How would you see a legislation that would allow the State to always make use of dead people's organs without previous authorization?
a. As a great gesture of solidarity
b. As an abuse of authority
c. As an efficacious way not to waste or- gans that are needlessly lost
d. As an offense to the family of the deceased

